\title{
LA CIENCIA OSCURA Y LA TECNO-UTOPÍA: LA ALTERNATIVA CONSERVADORA DE C. S. LEWIS
}

\author{
MARIO RAMOS VERA \\ Universidad Pontificia Comillas
}

\begin{abstract}
RESUMEN. Frente al auge de las utopías científicas, ilustradas y progresistas de finales del s. XIX se alzaron ofertas de sentido alternativas. Algunas fueron articuladas a través de un pensamiento conservador y una metanarrativa cristiana, trascendente y ultramundana. Recurriremos al ejemplo de C. S. Lewis, que presentó su respuesta a la tecno-utopía en su ensayo La abolición del hombre así como en la novela Esa horrible fortaleza, conclusión de la Trilogía cósmica (o Trilogía de Ransom). Presentaremos su impugnación por medio de tres argumentos distintos: (1) frente al proyecto de condicionamiento de la personalidad, la educación es un vínculo de continuidad con el pasado y de respeto hacia la tradición; (2) ante el ateísmo metodológico de estas distopías, Lewis defenderá el fundamento metafísico y trascendente de la imperfecta condición humana; (3) responderá a la arrogancia de la ingeniería social y política que reduce el poder a un criterio técnico de saber instrumental con el modesto lenguaje de la política.
\end{abstract}

PALABRAS CLAVE: utopía, distopía, agustinismo, conservadurismo, ciencia ficción, tecnocracia, clase dirigente, ciencias del comportamiento, naturaleza humana.

\section{Dark science and techno-utopia: the conservative approach of $C$. S. Lewis}

ABSTRACT. The rise of scientific, illustrated and progressive late nineteenth century utopias triggered proposals with alternative meanings. Some of those were articulated through a conservative thought as well as a christian, transcendent and otherworldly metanarrative. C. S. Lewis, for example, provided his answer to the techno-utopia in his essay The Abolition of Man as well as in the novel That Hideous Strength -conclusion of the Cosmic Trilogy (or Ransom Trilogy). We will introduce his challenge through three different arguments: (1) contrary to the project of personality conditioning, education is a link of continuity with the past and of respect for tradition; (2) in the light of the methodological atheism of these dystopias elicited the metaphysical and transcendent lewisian foundation of the imperfection of the human condition; (3) He will reply to the arrogance of social and political engineering by reducing power to a technical criterion of instrumental knowledge with the modest language of politics.

KEY WORDS: utopia, distopia, augustinism, conservatism, science fiction, technocracy, power elite, behavioural sciences, human nature.

Si el transhumanismo, las intervenciones para condicionar la personalidad o la posibilidad del cambio ontológico de la naturaleza humana nos interpelan sobre la propia condición del hombre, haríamos bien en recordar que no se trata de cuestiones exclusivas de nuestro acelerado momento histórico. Encontramos resonancia en los esfuerzos que las tecno-utopías, desde el poder, el saber y las mediaciones tecnológicas han realizado para dilucidar — más allá de lo meramente físicoqué es la naturaleza humana. Si a lo largo de su dilatada historia el caudal del 
pensamiento utópico ha revestido distintas formulaciones, no resultaría casual el auge durante el s. XIX de las utopías científicas, herederas de la ciencia, la tecnología y la idea de progreso indefinido. Un buen ejemplo lo encontramos en el escritor Herbert George Wells (1866-1946), con sus anticipaciones del futuro que incluían elementos de las ciencias sociales, de la filosofía y del socialismo fabiano. A su vez, se alzaron voces para denunciar la deriva siniestra de las utopías tecno-científicas, en ocasiones deudoras de una metanarrativa cristiana, metafísica y trascedente, vertebradas al tiempo sobre los principios del pensamiento conservador — tradicionalismo, organicismo, prudencialismo y escepticismo político-. Dentro de este linaje de pensadores disconformes con el sueño de un mundo bajo el paradigma científico nos centraremos en la impugnación del académico y literato Clive Staples Lewis (1898-1963) frente al discurso tecno-utópico. Tal y como queremos mostrar, presenta una alternativa conservadora — como disposición y mentalidad antes que doctrinalismo partidista- deudora de la ley natural y de una metanarrativa celeste. Para comprobarlo atenderemos a dos de sus obras: el ensayo La abolición del hombre y el tercer volumen de la Trilogía Cósmica, titulado expresivamente Esa horrible fortaleza.

El primero de estos libros, La abolición del hombre, es la versión publicada de las tres conferencias que el profesor Lewis pronunció en el Riddell Memorial, de la Universidad de Durham, los días 24, 25 y 26 de febrero de 1943. Con la excusa de refutar dos libros de texto escolares, impugnará, por medio de la ética y de la ley natural, la hegemonía del relativismo imperante en la moderna cultura occidental. En el segundo libro, Esa horrible fortaleza (1945), por medio de los vistosos colores de la narración fantástica profundizará en la perspectiva terrible de un salto ontológico por medio de un hombre post-humano. Concluirá así la utopía cosmológica, edénica y cristiana que comenzó en 1938 con Más allá del planeta silencioso y que continuó en 1943 con Perelandra. Un viaje a Venus. El tercer volumen contiene una confrontación dualista y agustiniana nada disimulada entre la ciudad celeste y la ciudad del hombre, por medio del enfrentamiento entre una comunidad de seguidores de la ley natural, respetuosos con la tradición y la sociedad organicista frente a un organismo tecnocrático - el Instituto Nacional de Estudios Coordinados (N.I.C.E. en inglés, acrónimo que no es casual) — en el que interactúan personajes de nombres significativos como el Sr. Frost, Wither, Feverstone o la Sra. Straik. Procederemos a continuación a exponer los elementos que articulan la impugnación del proyecto tecno-utópico cientificista que vertebra Lewis: (1) la educación como un vínculo de continuidad con el pasado y de respeto con la tradición; (2) el esfuerzo apologético de defensa del fundamento metafísico y trascendente de la condición humana frente al ateísmo metodológico y el cientificismo de las utopías tecnológicas; y (3) el modesto lenguaje de la política en contraste con la arrogancia de la planificación racional.

(1) El primer postulado de Lewis señala que la anomia, la especialización técnica y el abandono de las materias clásicas habrían dejado de lado la educación como formación integral de las dimensiones de la persona para responder a un proyecto de barbarización, condicionamiento y manipulación de la personalidad. Sus palabras son claras: "No es una teoría lo que les están metiendo en la cabeza, sino que les hacen asumir algo que, diez años después, una vez olvidado su origen y 
siendo inconsciente su presencia, les condicionará a la hora de tomar parte en una controversia que nunca habrán reconocido como tal» ${ }^{1}$. Lewis contrapone a este experimento nivelador una serie de elementos propios del conservadurismo. A saber: la continuidad del vínculo con el pasado, la lealtad hacia la experiencia, y el conocimiento como una condensación de aquello que nos ha sido legado y que funciona, decantado por el peso de la historia. Algo que Lewis nos confirma en el propio ensayo: «la diferencia entre la antigua y la nueva educación será importante. Mientras que la antigua formaba, la nueva simplemente "condiciona" ${ }^{2}$. La advertencia del profesor Lewis sobre la corrupción de la formación educativa también tendrá su correlato literario en la conclusión de la trilogía cósmica. En Esa horrible fortaleza, el Sr. Frost tratará de re-educar a uno de los protagonistas —Marck Studdock- por medio de un entrenamiento sistemático en lo que el N.I.C.E. denomina «objetividad», que no es otra cosa que una educación orientada a suprimir los valores, conocimientos y preferencias propiamente humanos. Uno de sus utopistas tecnológicos, Lord Feverstone, aseverará que el problema del hombre se solucionará mediante la «esterilización de los incapaces, exterminación de las razas atrasadas... reproducción selectiva... Después verdadera educación, incluyendo educación prenatal... a la larga llegaremos al condicionamiento bioquímico y a la manipulación directa del cerebro» ${ }^{3}$. Sus palabras nos parecen lo suficientemente explícitas.

(2) En segundo lugar, la impugnación del utopismo dogmáticamente científico, progresista y ateo estará personificada en el escritor Herbert George Wells —a quien Lewis dedica la trilogía cósmica y a quien caricaturiza como periodista en este tercer volumen de la saga-. Más concretamente impugnará el rechazo a las ideas de pecado original y de Dios providente. El rechazo del pecado original también nos orientará en la concreta disposición conservadora de Lewis, manifiestamente cristiana. Para ello recurriremos a Anthony Quinton, que en su obra The Politics of Imperfection. The religious and secular traditions of conservative thought in England from Hooker to Oakeshott desarrolló la tesis de que en el conservadurismo inglés conviven dos tradiciones: (a) Una de ellas es el conservadurismo religioso, que sustenta la premisa conservadora de la imperfección de la naturaleza humana en la doctrina del pecado original, vinculándose con una ley natural, un orden providencial y un fundacionalismo metafísico, recordándonos así que cada persona es un reflejo único del infinito. (b) En segundo lugar, contaríamos con la tradición conservadora secular, que situaría la imperfección del hombre en un plano intelectual y se articularía desde un punto de vista, un lenguaje y una disposición más contextuales ${ }^{4}$.

\footnotetext{
1 Lewis, C. S., La abolición del hombre, Ediciones Encuentro, Madrid, 1990 (4ª ed. 2007), pp. 10 y 11

2 Ibíd., pág. 26.

3 Lewis, C. S., Esa horrible fortaleza, Vol. III, Trilogía cósmica, Minotauro, Barcelona 2006, p. 51.

4 Quinton, A., The Politics of Imperfection. The religious and secular traditions of conservative thought in England from Hooker to Oakeshott, Faber and Faber, Londres 1978, pp. 16-17.
} 
(3) Tercero, tal y como recoge el tercer capítulo de La abolición del hombre, Lewis censurará la arrogancia de la planificación racional que reduce el poder a un criterio técnico de saber instrumental. Así, es este capítulo presentará lo que sería del futuro de la humanidad sin el ancla de valores morales tradicionales al tiempo que pretende responder a la pregunta sobre quién limita la razón técnica en ausencia de una ley natural. La respuesta no puede ser alentadora para quien cree que el mundo no es tan inteligible y maleable como otros se empeñan en hacer creer. Tampoco puede serlo para quien considera que las aristas más afiladas de la existencia muerte, mal y sufrimiento- no son elementos temporales sino limitaciones permanentes. A juicio de Lewis, el mito ilustrado del progreso indefinido y la concepción del mundo como una empresa sin terminar sería una distopía. Como él señala: «Lo que llamamos el poder del Hombre es, en realidad, un poder que poseen algunos hombres, que pueden permitir o no que el resto de los hombres se beneficien de él $»^{5}$. De ahí que la preeminencia creciente de las soluciones técnico-científicas, la concentración del poder instrumental y la presunción de poder construir exitosamente una sociedad carente de conflictos supongan la clausura de la política considerada como diálogo, conflicto o pluralidad para adecuarla a una metanarrativa de la eficiencia. Esta ingeniería social, genética y escrita en borradores abstractos de una sociedad ideal entroncaría con la denuncia del conservador Roger Scruton, que denuncia la ilusión de poder reinventar todo de nuevo ateniéndonos a un plan racional ${ }^{6}$. Surgiría una casta de tecnócratas capaces de proyectar el perfeccionamiento de la humanidad. Así, la capacidad de manipular y condicionar a las siguientes generaciones no será en absoluto pacífica, pues los «últimos hombres, lejos de ser los herederos del poder, serán sobre todo los más sujetos a la mano mortal de los grandes planificadores y manipuladores, y serán menos capaces de ejercer un poder sobre el futuro ${ }^{7}$. El rechazo del profesor Lewis hacia esta osadía intelectual de planificación racionalista aparecería consignada con tal fuerza en Esa horrible fortaleza que Russell Kirk se haría eco en su célebre obra The Conservative Mind al aludir a ese mundo marchito y estéril dirigido por unas élites tecnológicas dominantes ${ }^{8}$. Uno de los jerarcas que aparecen en la novela de Lewis, Filostrato, alcanzará la apoteosis de su ciencia oscura al proponer el salto ontológico de la humanidad y abandonar la corporeidad por medio de prótesis epistemológicas: «El nacimiento, la procreación y la muerte. ¿Qué pasaría si descubriéramos que la mente puede vivir sin cualquiera de las tres?»" A mayor abundamiento, el urbanista Mumford reconocería en estas líneas de Lewis la denuncia de las corrupciones psicológicas mórbidas subyacentes en las fantasías técnicamente avanzadas ${ }^{10}$.

5 Lewis, C. S., La abolición del hombre, Ediciones Encuentro, Madrid, 1990 (4ª ed. 2007), p. 56.

6 Scruton, R., Usos del pesimismo. El peligro de la falsa esperanza, Editorial Ariel, Barcelona, 2010, p. 197.

7 Lewis, C. S., La abolición del hombre, Ediciones Encuentro, Madrid, 1990 (4ª ed. 2007), p. 59.

$8 \mathrm{KIRK}_{\text {s }}$ R., The Conservative Mind. From Burke to Eliot, Regnery Publishing Inc., Washington D.C., 2001, p. 469.

9 LewIs, C. S., Esa horrible fortaleza, Vol. III, Trilogía cósmica, Minotauro, Barcelona, 2006, p. 223.

10 Mumford, L., The Pentagon of Power, Vol. II, The Myth of the Machine, A Harvest/HBJ Book, San Diego, 1970, p. 220. 
Concluimos con la cristalina advertencia que Lewis nos traslada, por medio de La abolición del hombre, sobre cuál sería el resultado final de este horripilante experimento: «la Naturaleza no se volvería a preocupar de la inquieta especie que se revolvió contra ella hace ya muchos millones de años; no sería molestada ya más por la cháchara de la verdad, de la compasión, de la belleza y de la felicidad». Por tanto, frente al sueño de la eficiencia, de la tecnología y del hombre nuevo, Lewis presentará su alternativa por medio de su trasunto literario Elwin Ransom —el protagonista de la trilogía cósmica- y la comunidad que le secunda, denominada muy significativamente la «Hermandad del Rey Pescador». Sus líneas de actuación responderán, sustancialmente, a los principios o cánones del conservadurismo convencionalmente aceptados. En este sentido, tanto Ransom como sus compañeros concebirán la tradición como argumento distendido a través del tiempo para definir y redefinir ciertos acuerdos fundamentales de acuerdo a las circunstancias. Asumirá las limitaciones naturales del hombre, corregidas por medio del principio de autoridad y de la cohesión social. Para él la sociedad sana responderá a un modelo orgánico y apenas sujeto a una intervención mínima. Para los personajes de la Hermandad del Rey Pescador la supervivencia estará condicionada por el recurso a sus raíces históricas — propias de la mitología artúrica-. Este reverso simétrico de los sueños de la ciencia oscura, nos recuerda Lewis, descansa en la premisa de que la condición humana es reflejo único de aquella Llama eterna que, según San Juan, no se apagará nunca (Jn 1, 5). Frente al remedo transhumanista de maquinaria, eficiencia y planificación racional, el profesor Lewis ofrece los fundamentos metafísicos y una disposición conservadora para transitar desde la ciudad de ese hombre "nuevo» hasta alcanzar, como peregrinos y aventureros, nuestro verdadero hogar: la ciudad celeste.

Universidad Pontificia Comillas

Mario Ramos Vera

Mario.ramos.vera@gmail.com

[Artículo aprobado para publicación en diciembre de 2016] 